\section{Conserving photos}

The Getty Conservation Institute has published a new title, Issues in the Conservation of Photographs. The 752-page paperbound anthology chronicles the emergence and development of photograph conservation as a professional discipline. It includes 72 texts published from the 19th through the 21st centuries that are essential to understanding the key issues of photo conservation. Many of the texts (e.g., lectures, memos, and letters) have never been published. The book was edited by Debbie Hess Norris and Jennifer Jae Gutierrez of the Art Conservation Department at the University of Delaware.

The book costs $\$ 70$ and is available from the Getty Bookstore at www.getty.edu /bookstore/titles/photocons.html. ISBN: 9781-60606-000-1.

\section{Framing photos}

The Image Permanence Institute (IPI) has mounted "A Consumer Guide to Materials for Preservation Framing and the Display of Photographic Images" on its Web site. The brochure covers the anatomy of a frame package, causes of photo decay, best practices for framing, and recommendations for display. It joins four other guides about family photos: "A Consumer Guide to Traditional and Digital Print Stability," "A Consumer Guide for the Recovery of Water-Damaged Traditional and Digital Prints," "A Consumer Guide to Modern Photo Papers," and "A Consumer Guide to Understanding Permanence Testing."

All five guides are available free-of-charge at www.imagepermanenceinstitute.org /shtml_sub/downloads.asp.

\section{NEDCC Webinars}

The Northeast Document Conservation Center (NEDCC) is offering Preservation 101 as

Jane Hedberg is senior preservation program officer at Harvard University Library, e-mail: jane_hedberg@ harvard.edu; fax: (617) 496-8344 a live online Webinar starting October 26, 2010. It is a six-month course consisting of 11 Webinars plus offline study and assignments. It will cover an introduction to preservation, deterioration of paper, film, electronic media, buildings and environments, collections care, analog and digital reformatting, conservation treatment, disaster planning, and building a preservation program. Donia Conn will be the instructor.

NEDCC is also offering individual twohour online Webinars. The first is "Surveying Your Collection" on August 25, 2010, the second is "Storage and Handling of Collections Materials" on September 22, the third is "Environmental Control and Monitoring" on October 21, the fourth is "Pest Management" on November 17, and the fifth is "Collections Security" on December 15. All Webinars start at 2 p.m. EST.

Preservation 101 costs $\$ 600$ and the registration deadline is October 22. The individual webinars cost $\$ 95$ each. For more information, go to www.nedcc.org/education /training.calendar.php.

\section{University of Illinois AvSAP}

The University of Illinois Library has completed the Audiovisual Self-Assessment Program (AvSAP), a three-year, IMLS-funded project to develop a Web-based tool to help collections managers with little AV expertise to devise preservation plans for their collections. The AvSAP software uses information about format type, physical condition, and storage condition to determine preservation priorities. It can be used for either individual item or random sample surveys. It provides pop-up windows with illustrated background information about AV definitions and concepts that can be used by the surveyor when wanted. Lastly, it produces a report of the findings to support decision-making.

Access to the AvSAP is available free-ofcharge at www.library.illinois.edu/prescons lavsap. $n$ 